
Not for reproduction, distribution or commercial use.

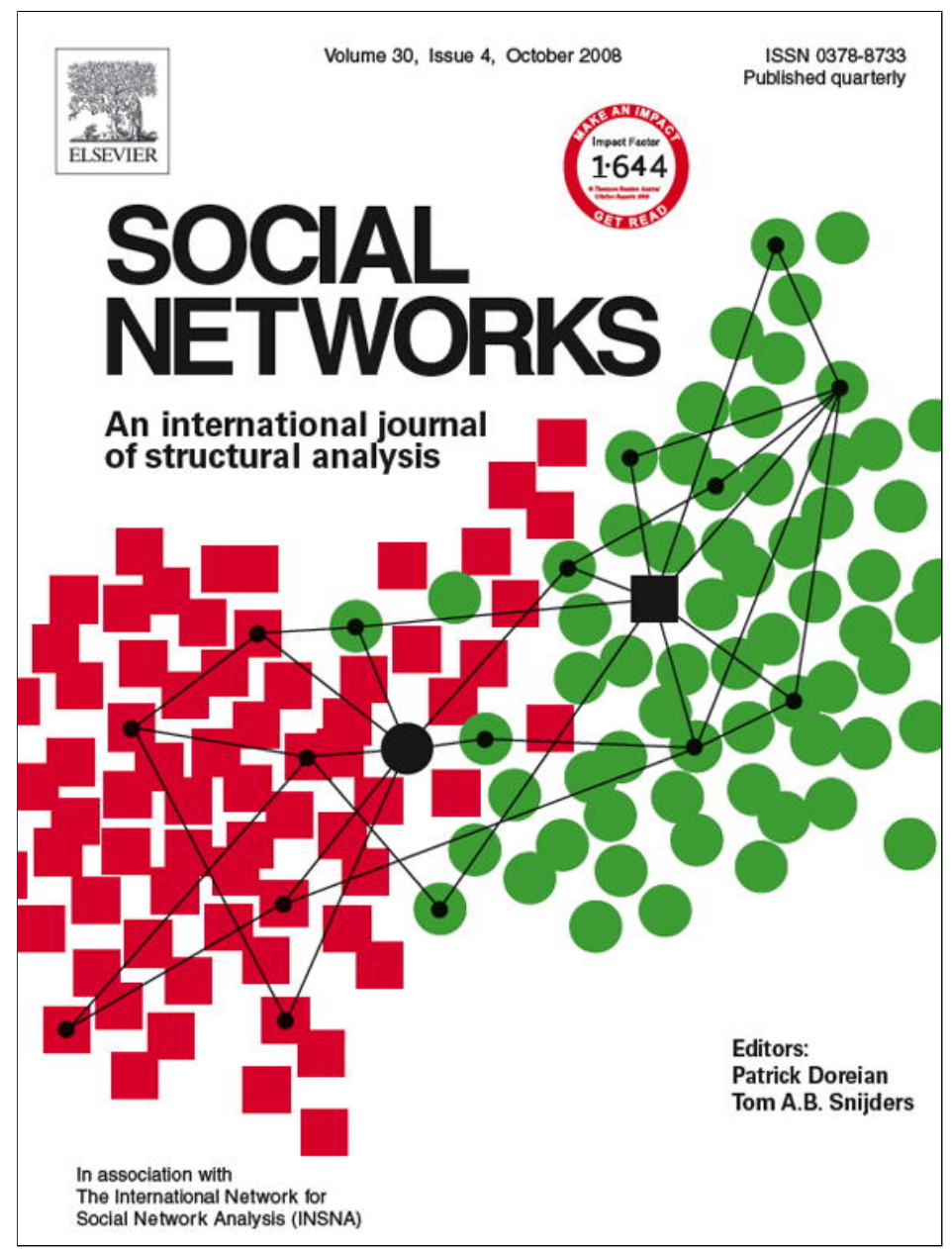

This article appeared in a journal published by Elsevier. The attached copy is furnished to the author for internal non-commercial research and education use, including for instruction at the authors institution and sharing with colleagues.

Other uses, including reproduction and distribution, or selling or licensing copies, or posting to personal, institutional or third party websites are prohibited.

In most cases authors are permitted to post their version of the article (e.g. in Word or Tex form) to their personal website or institutional repository. Authors requiring further information regarding Elsevier's archiving and manuscript policies are encouraged to visit:

http://www.elsevier.com/copyright 


\title{
What are friends for? Elective communities of single people
}

\author{
Elisa Bellotti* \\ Department of Social Science, University of Turin, via S. Ottavio 50, 10124 Turin, Italy
}

\section{A R T I C L E I N F O}

\section{Keywords:}

Friendship

Community

Single youth

Social network analysis

Qualitative study

\begin{abstract}
A B S T R A C T
The paper presents the results of a qualitative research on friendship networks of single people. The research has been undertaken using social network analysis tools (egonetworks) and qualitative interviews, on a non-representative sample of 23 heterosexual singles of Milan, aged between 25 and 35 years, 12 male and 11 female.

Framed within the theory of community, we formulated some questions that are addressed through the analysis: the role of friendship in single people's everyday life, which in some cases substitutes the traditional family as a source of emotional, social, material and economical support; the possibility that friendship is not always intended as a source of support, and people can name friends even if they do not provide any kind of support; the effect of the network structure on the strength of dyads, that will easily disconnect if not embedded in a cohesive network.

Four different kinds of friendship networks have been found: the small cliques, the company, the core/periphery structure, and the contextualised components. In the discussion section, empirical findings are analysed focusing on different strategies of friendship, and special attention is given to the gender issue.
\end{abstract}

(c) 2008 Elsevier B.V. All rights reserved.
Sociological debate has often focused on the problem of Individualism. During the Enlightenment this phenomenon was considered a sign of freedom from the ascribed privileges and the inflexibility of traditional societies, however since the XIX century Individualism has shown a dark side that threatens community and causes loneliness (Elliot and Lemert, 2006). Individualization has therefore been interpreted as a process of atomization of society, implying the loosening of values and the fragmentation of social structure. It is rooted in the transformations of the first and the second industrial revolutions (of production and communication), the effects of secularization, the 60's cultural revolution and the rise of new social science subjects like youth and feminist studies. These transformations have been reinforced by the process of globalization, which not only opens new geographies of opportunities but also increases the problem of fragmentation. Ironically, in a more connected world it seems that people are left alone in facing the growing complexity of a system with no values, no boundaries and no institutions (Bauman, 2001).

This paper focuses on one of the main aspects of the individualized society related to the personal private sphere. The transformations of intimacies (Giddens, 1994) have challenged the

\footnotetext{
* Tel.: +390116702617.

E-mail address: elisa.bellotti@unito.it.
}

persistency of primary ties: these relationships, although considered to be the basis of community, are affected by a deep process of modification that radically changes them. Bauman claims that today traditional relations are considered "like Ribena: imbibed in concentration, they are nauseating and may prove dangerous to health-like Ribena, relations should be diluted when consumed" (Bauman, 2003: X).

It has been claimed that the processes of weakening primary ties is partially responsible for some of the changes in traditional communitarian relationships. However as we will see in the first section of this paper many scholars have challenged this position as it lacks of empirical evidence. Fischer, for example, says that "we can evaluate the loss of community thesis only by closely studying people's personal relations, the social world these relations are embedded, and the ways urbanism affects the choices and constraints people face in building their relations" (Fischer, 1982a: 1). Following this perspective, other scholars argue that in contemporary times friendship has increased its importance in everyday life, as people now refer to friends for different tasks and in different periods of life (Roseneil and Budgeon, 2004; Spencer and Pahl, 2006; Ghisleni and Rebughini, 2006).

Friendship, as a relationship characterised by lightness, nonexclusivity and temporality, seems to be today the archetype of affective relationship. Family and neighbours ties are not taken for granted anymore, and people can chose, between their ascribed relationships, whom they prefer to relate to, how often, what and if 
they want to exchange. Thus, traditional community bonds are now shaped by choice as this has always been considered the typical trait of friendship. In addition friendship does not imply a simple dyadic structure, but a multiplex and network structure. The strength of friendship lies in its informality, as friends can be a valuable source of social capital to each other without being linked by any obligation (like family or colleagues). However friendship is a private relationship that never gains an institutional status: its growing importance can be understood as a sign of the privatization and deinstitutionalisation of society, a process described by Sennet (1978) as the rise of an intimate society. This is why some of the studies on social capital have undermined its importance focusing their attention on institutionalised forms of social cohesiveness, like leagues, trades and associations (Putnam, 2000). Fischer (2005), revising Putnam's work, criticises this approach because it fails to show how people still strongly relate to others even if they do not belong to any institutionalised form of association.

While the centrality of friends and peer groups during childhood and adolescence has been extensively studied (see for example Gifford-Smith and Brownell, 2002; Giordano, 2003), as well as friendship between coupled adults (classic studies include Bott, 1956; Allan, 1979) this paper examines the role of friendship for single people focusing on young adults, in order to see what are the specific roles of friends during the transition to adulthood. Using a qualitative approach we study singles' friends, examining their role and describing and classifying some possible (but not exhaustive) shapes friendship networks can take. We wish to explore the relational styles of single young adults because they are usually considered the people most influenced by Individualism: they seem to be "desperate to relate; yet wary of the state of being related and particularly to be related for good" (Bauman, 2003: VIII), and they deliberately delay the transition to adulthood.

The first two sections present the theoretical background of some of the main studies on community and friendship. The third section reports a qualitative study on the structure and the meaning of friendship networks of single people living in Milan, Italy. Data are analysed in the fourth section addressing the questions formulated in the earlier part of the paper. The last section discusses the main empirical findings and challenge the idea of a possible centralization of young adults intimacy around friendship (Roseneil and Budgeon, 2004), with particular attention paid to gender differences.

\section{Affective relationships as tracks of community}

Since the XIX century sociology has considered affective relationships as opposed to instrumental ones. The classic authors thought that these two kinds of ties were at the base of two different social structures. Affective relations, characterised by intimacy and spontaneity, were typical of community (Tönnies, 1955); they were examples of affective agency (Weber, 1978) driven by mechanical solidarity (Durkheim, 1984). Affective relationships have therefore been used by classic authors to describe a model of interactions which emerged from the industrial society founded on the rational and logic nexus. The classic authors were more able to describe instrumental action rather than the affective because at that time the first one was more problematic.

Western societies at the end of the XIX century were crossed by deep waves of transformation, entailing modifications not only of the macro assets of economy and society, but also of the micro foundations of social action and interaction. The process of industrialization and urbanization gave rise to a more complex bureaucratization and rationalization of society, the division of labour lead to a division of the public and the private sphere, the affirmation of bourgeoisies defined the public and the private in terms of gendered territorial boundaries, distinguishing between the masculine life at work and the feminine caring about the house. Focusing on the rational aspects of action classic authors described affective relationships as an instinctive residue (Pareto, 1963), whose unpredictable effects, due to their irrational nature, could not be consciously controlled either by the actor or by the observer: it could only be justified after the action was concluded (Weber, 1978).

Only Simmel $(1950,1984)$ dedicated special attention to the role of emotions in social interaction, criticizing the reduction of human life to rational/logic principles. In Simmel's view the emotional sphere is an essential part of individuality that cannot be reduced to the rational one because it follows its own logic and dynamics. Some emotional manifestations, like love and friendship, lie outside the utilitarian system of exchange. Nevertheless Simmel claims that the process of urbanization modified the practices of interaction, as it encouraged and rewarded blasè behaviour (Simmel, 1950) that is typical of people who relate to others through intellect rather than emotions. When the density of the population increases it is not possible to directly relate to everyone else, thus relationships necessarily become impersonal and mediated by the exchange value.

The loosening of affective ties is then a process that classic authors associate to urban development and the city becomes the symbol of modern society (Bagnasco, 1999): here the relational circles are substantially different form the ones of small villages. Thus, the idealtypic opposition between community and society gains an historical dimension and marks a shift from pre-modernity to modernity. This shift, as Bagnasco said, entails a loss of collective identities due to the "difficulties for the individual in adapting to a context characterized by high uncertainty and variability" (Bagnasco, 1999: 30). It also entails a loss of reciprocity that was instinctive in communities but now needs rules in societies and a transformation of trust, once founded on shared values and traditions, today affected by the secularization and fragmentation of global and local cultures. These are some of the community debate threads that are still under discussion today: in this paper we do not concentrate on the political and economical aspects of the macro modifications of societies, but on the transformations of intimacy cultures, on the kind of support that affective ties provide and on their gender specialization.

Affective relationships first of all include family and couple ties, which are both under challenge today. Family ties were the roots of modern marriage and the symbol of the romantic love paradigm (Giddens, 1994), a paradigm that partially substituted, during the XIX century, the economic and religious agreement at the base of pre-modern marriage. Today family seems to be in a deep crisis facing the rise of "pure relationship, a social relation which is entered into for its own sake, for what can be derived by each person from a sustained association with another; and which is continued only in so far as it is thought by both parties to deliver enough satisfactions for each individual to stay within" (Giddens, 1994: 58). Bauman talks about liquid love, a temporary form of connection where sacrifice and commitment are banned and where "you can always press delete" (Bauman, 2003: XII). This is supposed to be true especially for youths whose age is at the boundaries of adulthood and are born in the individualist society and are dominated by consumption and the contraction of time. Contemporary young adults do not know the meaning of waiting and are not prepared to make the effort for conquest (Cavalli, 1985). Consequently they find it hard to conceptualise love and feelings as something that involves long-term commitment and devotion. Within this scenario affective ties cannot be considered as sources of long lasting support: they do not provide stable identities and faith and they tend to be 
substituted by the figure of the expert (Giddens, 1994; Bauman, 2000), who is a symbol of late modernity.

Traditional community ties also include neighbourhood which provides a source of informal solidarity based upon common spaces, culture and values. Again, the high mobility, multiculturalism and fragmentation of urban societies seem to loosen the traditional neighbourhood ties and to go along with the neocommunitarism stream that blames the individualisation and atomisation of contemporary society (Bellah, 1985; Etzioni, 1993; Putnam, 2000). Some years ago Gans has shown that it is possible within the metropolis to identify some "urban villages", where "the interaction is more intimate than a secondary contact, but more guarded than a primary one" (Gans, 1999: 68): nevertheless, neighbourhood solidarity seems today to be relegate to the bucolical idealization of country life (Williams, 1973). Thus, part of the sociological literature seem to agree with the classic authors' conclusions about the decline of affective relationships as a sign of the weakened community. But as Fischer (1982a, 2005) pointed out this pessimistic perspective fails to consider the last typology of relationship (after family and neighbours) that Tönnies (1955) considered at the base of traditional community: the elective one, which is mainly formed by friendship ties, that are in Tönnies' words "the truly human and supreme form of community" (1955: 48). Friendship is nevertheless different from family and neighbours, as it is not regulated by any institutional dimension: thus, in Tönnies' words, "such a tie must be made and maintained through easy and frequent meetings, which are most likely to take place in a town" (1955: 49). While family is weakened by the new form of temporary ties typical of friendship, and while neighbourhoods are fragmented by high mobility and the ethnic multiplicity of urban life, cities seem to favour the rise of importance of friendship, where the responsibility of maintaining the tie lies with the voluntary intention of the actors involved.

\section{Is always friendship a source of multiplex support?}

The only traditional affective tie that seems to last today is friendship, the elective and virtuous relationship that has been considered since ancient times as a pure and disinterested manifestation of morality (Aristotele, 1992). Sociologists started to intensively study friendship only in the '70s (with exception of the Chicago School, see for example White, 1943), and this late interest is especially evident in Italy, where there has been a focus on the sociology of family and urban sociology, but the sociology of friendship is not as well establish. There are only a few dedicated studies (Di Nicola, 2002, 2003; Ghisleni and Rebughini, 2006), while the international literature has several important contributions to the topic (Allan, 1979; Fischer, 1982a,b; Wellman, 1979, 1990; Bidart, 1991, 1997; Heat and Cleaver, 2003; Heat, 2004; Roseneil and Budgeon, 2004; Bidart and Lavenu, 2005; Spencer and Pahl, 2006).

One of the main problem is to identify some sociological tools to describe the most private relationship: although philosophy analyses the meaning of friendship and psychology points out the traits of personality involved in it, sociology is still constructing a general phenomenology of friendship correlated to structural features like age, gender, ethnicity, class, and so on. Philosophers consider friendship the most elective relationship, as it is freely chosen and less determined by instrumental constrains. Di Nicola (2002), following Zweig (1980), suggests that ancient societies viewed friendship as a virtue because it was the only interaction where choices were possible. Within ancient societies people occupied fixed ascribed social positions and socialization was restricted to those who share the same social status. Friendship was then the only relationship in which it was possible to be free from social con- strains and to subvert the fixed social order. This is the reason why friendship is still considered nowadays the relationship of choice, opposed to family and neighbourhood ties. In fact Adams and Allan (1998) show that we can fully comprehend friendship only taking into account the context in which it arises: we are free to chose our friends, but we will probably chose someone of our own age, our own gender, our own status and in our own neighbourhood. Garret (1989) claims that despite its elective nature friendship confirms, rather than subverts, the social order.

The second problem is that the term friendship is associated with a wide variation of meanings, thus it is difficult to use it as a sociological indicator. Fischer (1982b) observed that people intend very different thing when they talk about their friends: studying 1050 American adults, the author has found that the tag "friend" does not identify a particular kind of relationship, but it is used to name all the people who are considered important who do not belong to other categories such as family, neighbours or colleagues. This means that there is not a collective definition of friendship based on blood, territorial, or working nexus and its meaning only lies upon the quality of relationships (Allan, 1979; Fehr, 1996). A way to solve this problem is to use the name generator (Marsden, 1987, 2003), a technique which consists of asking people whom they go to when they need help for specific tasks, like borrowing money, looking after the house, talking about private problems, and so on. Then they are asked to define the kind of relationship every one is tied by. Thus, it is possible to identify specific functions of friendship, but this method collect data about relations starting from the roles they have, because it asks the interviewees whom would they turn to when facing specific needs. Bernard et al. (1990) identify four different methods for measuring the personal network. Some questions, like "who do you discuss important matters with" are dedicated to generate the emotional support group; some others, like "Who could take care of your house if you went out of town" elicit the social support group; another technique consist of asking an informant to recall the names of all the people he or she can remember. This could be done compiling a notebook of all the people meets over some period as well as showing the informant a list of names from a phonebook and asking him to indicate who does he or she knows. The last method is the Reverse Small World (RSW), were "informants are asked to name those members of their global network whom they could use as carriers of information to persons outside their global networks" (Bernard et al., 1990: 1981).

We purpose a slightly different version of the third method. While the first two are undoubtedly useful, they fails to map relations that do not provide any kind of support, but might be still considered important for the interviewee. The third one, as presented by Bernard et al. (1990) generates a network wider than the one we want to elicit here. Thus, we decided to ask interviewees to name their friends without giving any definition of the term. What they intended when they referred to friends was then explored through biographical interviews, in which people could explain why they named someone, what kind of relationship there is between them, how it started and developed through time. In such a way the analysis of the kind of support is a consequence of name generator, letting the interviewees free to name people even if they do not offer any kind of support, while in the way it has been used in other researches (Burt, 1984; McCallister and Fischer, 1983) the kind of support is the question by which names are generated.

Using the name generator technique Fischer (1982b) found that friends are specialized in offering companionship that is sharing interests and free time, while emotional support (talking about private matters) is provided by those defined as close. Even if there is a certain level of intimacy between friends, Americans prefer to count on strong ties when they face important problems. These ties also provide material support (helping with the house, doing 
the shopping, and so on). Studying the population of East York in Toronto Wellman $(1979,1982,1990)$ found similar results: exploring if community is lost, saved or liberated, the author translates the community concept into network measures. He measures the density and the shape of the relational structures in which people are embedded, and he finds that different folks provide different kind of support: relatives are specialised in emotional support, colleagues talk about work and hobbies, friends provide companionship and neighbours material support. Regardless of the percentages correlating different ties to specific kind of support, Wellman's work is particularly important because it divides the people interviewed according to their network's typologies. Full time working married men tend to name mostly relatives, who provide companionship and material support, but they do not receive any kind of emotional support, as it seems that they are not used to talking about private matters. Married housewives and single mothers name neighbours, specialized in emotional support; relatives, who provide material support; long distance friends, whom they mostly talk on the phone with. Full time working married women, like men, include in their network colleagues, by whom they obtain especially emotional support. Finally singles, both males and females, students and/or workers, name mostly friends, who are a source of companionship, emotional and material support. This kind of typologies suggest that the kind of support depends on the individuals specific needs (e.g. single mothers have different needs from single students); in addition males and females show differences in relational styles.

A similar study has been recently conducted by Spencer and Pahl (2006) on a sample of 80 people living in UK. Here the authors mapped the networks of supportive ties, identifying different relational styles according to age, gender and ethnicity of the interviewees. They use a definition of community that is not based on territorial boundaries or on differences between elective and ascribed ties, but on the concept of personal community, which is "a mode of relating in dense, multiplex, relatively autonomous networks of social relationship" (Calhoun, 1998: 391) that implies many different kind of bonds, from family to friends.

The gender issue seems very important and it is a welldeveloped topic in sociology. Gender differences in friendship and affective styles are correlated to specific male and female social history and to the gendered patterns of socialization. Authors agree on the fact that women seem to privilege face to face relationships, in which they share intimacies and talk about private matters, while men see their relationship as a context for shared activities that are faced side by side (Wright, 1982, 1991; Gouldner, 1987; O'Connor, 1992, 1998; Werking, 1997). Giddens (1994) suggests that these differences are rooted in the XIX century romantic paradigm and in the diffusion of the novel: women were the main consumers of novels and they contributed to the diffusion of the ideal of romantic love. They found in friendship between other women an ideal place to expose and discuss new forms of intimacy, where the bound was founded on personal similarities and free disclosure of emotions rather than the formality and etiquette of social roles, especially the marital relationship.

\section{The research project, the methodology and the sample}

The qualitative study presented here explores some of the issues that arise from previous research. The claim is that contemporary people typically relate to each other through the practice of temporary and superficial connections (Bauman, 2003), and this article is founded on the sociological literature affirming that these pessimistic theoretical perspectives lack empirical findings. If we shift the attention from the growing percentage of divorces and late marriages to the personal affective networks it is possible to identify new cultures of intimacy, where family is only one of the possible sources of support that constitutes the dense, multiplex and relatively autonomous personal communities (Calhoun, 1998).

Here we focus on friendship in order to explore the role of this relationship for single young adults, who by choice are delaying the transition to adulthood particularly regarding the formation of a family of choice. In Italy the phenomenon has been described by the term "long family" (Scabini and Donati, 1988), which refers to the tendency of youths to live with parents long after they finish studying and start work; young people are not pushed to gain independence, as they always have a safe nest to go back to. While it is useful to be at home to face the increasing complexity of the job market (youths can better deal with flexibility as they always have parents who give them economic support) and of the housing market (they are not forced to rent or buy a flat on their own), it is not as useful for the development of an independent and self sustaining personality. In providing a safe affective environment parents do not encourage their sons and daughters to take the risk of a love relationship. Banfield (1958) has called this phenomenon the "amoral familism" claiming that ethical principles only applied within the nuclear family, and hence weakening the development of a collective ethic that in turn leads to the decline of the community. The fact that in Italy youths tend to live with their parents long after they finish school and start to work produces a distortion which is also reflected in national statistics. The Italian National Institute of Statistics (ISTAT) surveys and the national household panels define "singles" as people who live on their own. These surveys thus aggregate people in many different situations, like youths, elderly and divorced, including those who prefer to live on their own even if involved in a romantic relationship-the LAT couples (Levin, 2004). They do not identify singles who live with their parents: for this reason we decided to examine people who consider themselves single, regardless of whom they live with.

The theoretical background of this study builds on Wellman's results (1982) where friendship ties were seen at the centre of single's personal community: some authors (Watters, 2003; Roseneil and Budgeon, 2004) claimed that singles are decentring sexual relationships and centring their intimate life on friendship. The goal here is to describe how friendship networks are structured in terms of a draft typology of the possible shapes: within these we wish to explore what kinds of support people gain, with particular reference to gender.

We interviewed 23 heterosexual singles of Milan, aged between 25 and 35 years, 13 males and 12 females. We selected individuals between these ages because this is the life period in which it is expected to enter into adulthood by leaving school, getting a job, finding a stable partner and forming a new family. These steps in the past required definitive decisions, while today no choices are irreversible: it is often possible to go back to education, to change profession, to leave families and partners and to modify life trajectories. Thus, the traditional boundaries cannot be used anymore to distinguish youth from adulthood and there is a need for a new approach in order to explore this delicate period of life. People were selected using snowball techniques: some of those interviewed were colleagues of friends of friends, some were contacted through customers of bars and shops, others by passing on the request via email. Thus, no one in the initial population was personally known by the researches, and we managed to differentiate the sample according to their educational background and different areas of the city they live in. We selected 7 people who left education right after junior high school ( 4 men and 3 women), 8 people who went to secondary school ( 4 men and 4 women) and 8 people who attended or are attending university ( 4 men and 4 women). The threshold to be included in the sample was simply the subjective perception of personal affective status. All the people who 
participated in this research consider themselves as single: it does not mean that they cannot date occasionally nor that they have not experienced important relationships in the past. This kind of sample resembles those who consider affective ties as "liquid relationships" (Bauman, 2003), consequently it is of interest to study if in this case friendship can last longer than love.

To construct the networks we first ask each actor to name their friends giving no definition of the term and setting no limits to the number of response. Then we asked them to indicate if they think there is a link between every pair of friends. Thus, we collected egonetworks of variable sizes and density according to the different meanings people associate with the term 'friend'. Respondents also compiled alters' attributes (age, gender, where they live, where they were born, whom do they live with, if they are single or partnered, their educational level, what job they do and how long they have known ego for). These egonetworks represents the perceived friendship communities, as we did not interview the alters we cannot be sure ego is aware of all the possible ties between alters. We decided to use this version of the name generator instead of the classic one (by which people are named according to the kind of support they provide to ego) because one of our questions is to see if friends are always a direct source of support or not. There can be friends who live far away or were close in the past, as well as friends who are embedded in cohesive subgroups even if they do not directly relate to ego. Thus, another question is whether there is a structural network effect on single ties: those bonds that are embedded in dense networks or subgroups have less probability of disconnecting than single dyads.

Then we carried in-depth interviews focused on friendship, allowing respondents to explain the criteria by which they included the people they named. The interviews were recorded and codified according to the themes arising during the interview: we collected data on all the alters named and on the specific meaning and function of every tie. We found a wide variety of different meanings of friendship: some respondents include within the network only intimate friends, from whom they obtain emotional support that consists of sharing inner thoughts. Some include also friends they spend leisure time with, despite the level of closeness. Someone also includes old friends whom they do not see anymore but are still considered important. During the interviews people frequently named acquaintances and described the differences between them and friends. Acquaintances are not included within the friendship networks, but they can be encountered in several social occasions like dinners, parties and events. Moreover, respondents sometimes refer to people whom they do not have a direct contact with, like friends of friends: these represent potential weak ties (Granovetter, 1973) that can be subsequently activated.

\section{Variations in friendship networks}

Before analyzing the different shapes of friendship networks, it is useful to give a general overview of the data in order to see who are singles' friends and what are the differences according to some attributes of the interviewees and the people they named, keeping in mind that our qualitative data cannot be generalized as the sample does not represent the entire single population of Milan. The average size of the networks is 10.47 nodes but with a wide variation between the networks (S.D. 6.07); the average density is 0.79 , with less variation ${ }^{1}$ between the networks (S.D. 0.18). Obviously, in these cases the density is a perception of ego, as it could be that

\footnotetext{
1 The variation coefficient of the size of the network is 0.579 , bigger than the one of the density (0.226).
}

Table 1

Number of people named by gender

\begin{tabular}{lccc}
\hline & Male & Female & Total \\
\hline $\begin{array}{l}\text { Male } \\
\text { Absolute value } \\
\% \text { Value }\end{array}$ & 80 & 37 & 117 \\
$\begin{array}{l}\text { Female } \\
\quad \begin{array}{l}\text { Absolute value } \\
\% \text { Value }\end{array}\end{array}$ & $68 \%$ & $32 \%$ & $100 \%$ \\
$\begin{array}{l}\text { Total } \\
\text { Absolute value } \\
\text { \% Value }\end{array}$ & 48 & 71 & 119 \\
& $40 \%$ & $60 \%$ & $100 \%$ \\
\end{tabular}

Total of values in rows: total amount of people named by ego gender, Total of values in columns: total amount of males and females named.

she/he is not aware of all the ties between the friends. The people interviewed named 236 alters: 128 are males, 108 are females. The men (12 cases) named 117 friends, 80 males and 37 females; the women (11 cases) named 119 friends, 71 females, 48 males (see Table 1$)$.

Women have named slightly wider networks than men (12.09 average size of female networks compared to 10.75 average size of male networks). These results show that the hypothesis that women have smaller networks of friends than men (Allan, 1979) needs to be explored: our data cannot be generalized but can indicate areas for further research. Moreover, female networks seem to be more heterogeneous in gender compared to male networks.

The average age of alters is 29.48 (S.D. 4.8), which demonstrates that networks show homophily by age (the average age of the sample is 30.43): being a relationship based on equality, it is to be expected that it flourishes between people of the same age. More interestingly, the people interviewed have known their friends for an average of $40.83 \%$ of their own age. This data shows that friendship is a relationship that can last for quite a long time, definitely longer than love relationships, as one of the interviewee said:

In 34 years I could probably evaluate only the dark side of love, what I could not get from it, the bad feelings of insecurity. Friendship does last long, while love, according to my experience, does not. My longest love relationship lasted three years, actually one, because in the other two there were only arguments. Thus for me love does not last, while friendship has a higher importance: I cannot compare few intense months of relationship with a woman, also from a physical point of view, to twenty years of intellectual relationship with a friend. MD34 ${ }^{2}$

The example of Daniele, a 34 years old man who works as a car seller and lives on his own, is just one of the many within our sample who declare to consider friendship more important than love. We cannot go in details about different typologies of singleness we found in our sample, not all of them having such a bad opinion of love, but what is it true is that these singles invest more on friendship than in love, as the first is perceived as a more stable and enduring tie.

Friendship is also homophilous on area of residence: out of 236 friends, $78 \%$ live in Milan, $9 \%$ in the surrounding area, $7 \%$ in other districts and $6 \%$ abroad. Thus, while it has been claimed that within

\footnotetext{
2 The interviews have been translated from Italian to English by the author of this article. All the interviews have been coded with a letter indicating the gender of the speaker ( $\mathrm{F}=$ female; $\mathrm{M}=$ male); a letter indicating the educational background $(\mathrm{M}=$ middle school; $\mathrm{D}=$ secondary school; $\mathrm{L}=$ degree $)$ and a number indicating the age of the speaker.
} 
the city people lose a sense of a spatial community as they do not relate to their neighbours, we agree with scholars who focused their attention on personal networks rather than on traditional ideas of communities: within the city, people might not know their closer neighbours (even if $10 \%$ of friends named are neighbours), but they do have friendship networks that are constituted mostly by people living nearby.

The networks show heterophily regarding the affective status of friends: out of $236,45 \%$ are single, $39 \%$ are partnered, $12 \%$ are married, $3 \%$ are separated and $1 \%$ are separated with a new partner. Having a partnered friend only means that the frequency of meeting is lower that the one ego has with single friends, while having a married friend (especially with children), which is more common within the older age group, also means being more aware of lifestyle differences. Seeing each other less, due to the rise of duties that a family entails, does not imply a less emotional attachment. On the contrary, it seems to favor the comparison between being single and being partnered, as the friends often talk about it and share good and bad feelings.

Finally, networks are homophilous on educational level: interviewees who left education right after junior high school ( 7 within our sample) named 16 people who left education at the same level, 27 people who went to high school and 9 people who attended (or are attending) university; interviewees who went to high school (8 within our sample) named 9 people who left education after junior high school, 72 who went to high school and 23 who attended (or are attending) university; interviewees who went or are going to university did not name anyone who left education after junior high school, 15 who went to high school and 65 who went or are going to university.

The analysis of network structures combined with the interviews show four main typologies of networks, that partially depend on the subjective meaning associated with friendship: due to the qualitative nature of this study results cannot be considered representative or exhaustive of all the possible structures of friendship networks. We present some of the cases that best illustrate our typologies: the code, size, density and kind of structure of every network are summarized in Table 2 .

Table 2

Summary of the structures found

\begin{tabular}{lcll}
\hline Code & Size $^{\text {a }}$ & Density & Kind of structure \\
\hline ML35 & 4 & 1 & Clique \\
FM30 & 4 & 1 & Clique \\
FL35 & 4 & 1 & Clique \\
MD29 & 4 & 1 & Clique \\
FM31 & 11 & 1 & Group \\
ML29 & 8 & 1 & Group \\
MM31 & 6 & 0.93 & Group \\
MM33 & 7 & 0.9 & Group \\
FM28 & 7 & 0.9 & Group \\
FD33 & 12 & 0.87 & Group \\
FL26 & 21 & 0.78 & Group \\
MD35 & 14 & 0.76 & Group \\
FD27 & 7 & 0.76 & Group \\
FD28 & 27 & 0.74 & Group \\
ML32 & 13 & 0.74 & Core/periphery \\
MD34 & 18 & 0.73 & Group \\
MM28 & 12 & 0.72 & Group \\
MD28 & 15 & 0.64 & Contextualized components \\
MM27 & 12 & 0.6 & Core/periphery \\
ML28 & 16 & 0.58 & Contextualized components \\
FL31 & 20 & 0.56 & Core/periphery \\
FD35 & 16 & 0.48 & Core/periphery \\
FL28 & 7 & $0 ., 47$ & Contextualized components \\
\hline
\end{tabular}

a The size value here comprehends ego as well, while within the paper I refer to the number of people ego named, thus the size is one node smaller.

\subsection{The small cliques}

Four respondents (one man and one woman who went to university, one man who went to secondary school and one woman who went to junior high school) named only three friends all connected which form cliques.

An example of this typology is the network of FM30, whom we call Antonia. Antonia is 30 , she left school at the age of 15 , she works in a industry and lives with her original family in a suburb of Milan. She named three friends (Stefania, Cristina and Selene) she had known since childhood as they live in the same area. The women frequently keep in touch by phone, but even if they are neighbours they do not see each other very often: Cristina spends most of the time with her boyfriend, Selene has recently lost a parent thus tends to stay at home with her family and Stefania often works during night hours and does not have much free time. Antonia's friends are mostly a source of emotional support funded on sharing inner thoughts through dialogue. Friends are specialised according to the kind of topics they discuss: Stefania, the only woman who has got a degree, is a good partner to discuss about politics, news, and general matters. Selene has recently been a valuable support in facing a personal problem. Antonia, who normally considers Stefania as the one whom she talks most with, preferred to discuss a delicate family problem with Selene: she thought that Stefania could be judgemental as sometimes her evaluations are strict, thus she turned to Selene who listened to her without giving the impression of judging. Cristina instead does not seem to provide any kind of direct support: Antonia does not see her very often and when she needs to talk she would rather go to one of the other two friends. But Cristina is still named in Antonia's clique of intimate friends, as when they organise to see each others (mostly at someone's place) she is the one in charge of calling the others and set the date for the meeting.

What is missing in this network is essentially companionship: Antonia would like to go out more, but none of her friends have time for it: a sense of frustration and loneliness emerges during the interview.

I had to deal with it, I had to calm down: sometimes I got up in the morning feeling exciting and full of plans, I called them but no one would like to go out. What was I supposed to do, go out on my own? At the beginning I was feeling very angry, I had so many discussion with them but there was nothing to do, they are what they are, they rarely go out. FM30

Here the status of singleness is not satisfactory because a partner is considered someone to share experiences with. When Antonia was a teenager she used to substitute love with a friend. She reports the friendship with Samanta, a girl she met in school: they used to go out everyday, to go dancing every weekend, to go on holidays together. They pretended to have an exclusive relationship, and promised each other not to go out with anyone else. This kind of friendship is more similar to a romantic relationship, an exclusive tie that is intended to last for good, and it did not come as a surprise when Samanta met a partner and stopped going out with Antonia.

While the paradigm of romantic love, that is under challenge today (Giddens, 1994), entails that a partner must be unique and last "until death us do apart", friendship is not exclusive and its endurance depends on friends' intentions. There are no contracts granting fidelity and eternity, thus the rules governing the relationship (the norms of relevance and equivalence described by Allan, 1979) are dealt only within the friendship itself, and have to be light and modifiable. 
Antonia now recognises how in the past all her friendships were intended as the one with Samanta: too exclusive to last, they were however a valuable source of all the kind of support Antonia needed.

Since I was a child I have been used to have someone who particularly cares about me. Now that it is not like that anymore I feel there is something missing, something I used to count on. FM30

Another example of small clique is the network of MD29: Tiziano is a blue-collar worker who went to secondary school and lives with his mother and sister in the suburbs of Milan. He named three friends (Enrico, Simone and Paolo) whom he has known since primary school and always played hockey with. Friendship has grown through the hockey, as the men regularly meet at least three times a week. Companionship is mostly provided by Simone, who lives in the neighbourhood: Simone and Tiziano see each other everyday mostly for a beer and a movie at Simone's place. Tiziano seems to be satisfied with his social life, even if he cannot afford to go out very often: he never had money to waste on leisure, thus he is always careful with his money and the time spent with friends has always been based more on the pleasure to be together rather than on the kind of activities. When they were teenagers they used to meet for an "afternoon snack":

We used to meet every afternoon, go to the supermarket, buy some food and drinks and eat in the park, always being aware of how much we spent. MD29

The relationship with Enrico provides instead mostly emotional and material support. Tiziano normally discusses private matters with Enrico and the two men always support each others in difficult situations:

Once Enrico was away from Milan. He was in a difficult affective situation, he asked me if I could reach him and I went there. MD29

Material support consists particularly of small favours, like borrowing the car or helping with house repairs. Enrico is an expert in DIY and engines but Tiziano is keen not to transform the relationship into dependence. As Alberoni said "friendship is not compatible with high needs (...) it has to be light, and this characteristic implies an exceptional need. Friendship is an occasional gift, not a reiterated charity" (Alberoni, 1984: 51-52). Recently Tiziano experienced an increased distance from Enrico because he was concerned that he relied too much on Enrico's help. Tiziano does not have a car anymore, and he does not want to call Enrico every time he wants to go out. He did not explain to Enrico the reason why he does not call him so often anymore, and this miscomprehension implies that friendship has lost the companionship it previously provided.

I did not like the fact I had to be dependent by him to go out, but I have never explained him why I do not call him anymore. Maybe he thought I just would not like to see him anymore, but I did not clear that out because I'm too proud to admit the dependence. MD29

Paolo's friendship instead does not provide any kind of support, as Paolo moved out of Milan when he got married, and the two men do not often see or talk to each other. While the relationship has changed in terms of support, Tiziano still considers Paolo one of his best friends and names him in the small network. This proves that we cannot reduce friendship to the kind of support it provides, as there can be friends whom we feel very close to even if there is not a frequent contact or exchange: we also have to take into account the relationship history and the bound intensity.

\subsection{The company}

The second typology of friendship network is the company: this is the most common structure we found in our sample, as 12 people's networks are shaped in this way, both males and females and from all the educational backgrounds. It has a variable size (from 6 to 27 nodes) and a high density (from 0.72 to 0.93 ). The company normally represents a group of friends ego hangs around with on a daily basis: it is considered as a whole entity in which single ties are less important than the group itself. Within the company there can be temporary subgroups arising from shared interests. The company mostly provides companionship, but specialised ties can be found within it.

Maria is a 28 years old woman who attended secondary school and lives with her mother in the suburbs of Milan. Her network is structured in a clique of 23 people plus two couples who do not belong to the main group. The clique represent the company she has known for nearly 10 years, while the four people on the right are the owner of the shops next to hers. She owns an ironmonger with her ex-boyfriend, who also introduced her to the actual friends.

The company usually meets every night in a park in Milan, where the people chat, organize nights out and weekends away. Subgroups are formed according to the kind of activity they want to do: some women go dancing to Latino music, some men share the passion

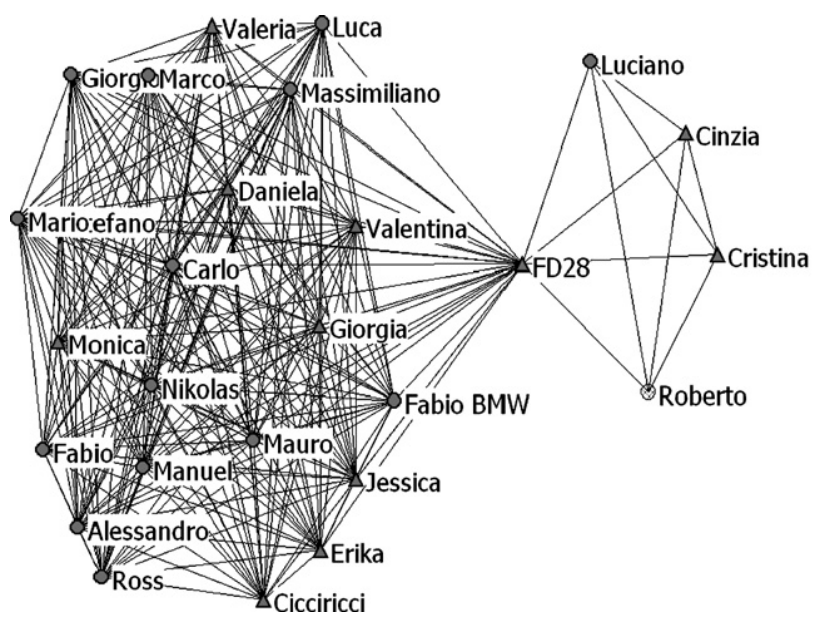

\author{
Size: 28 Nodes \\ Density: 0.74 \\ Circle $=$ Male \\ Up triangle $=$ Female
}

Fig. 1. Friendship network of FD28. 
for motorbikes, wealthy people prefer to go out to expensive bars and clubs in Milan (Fig. 1).

What is interesting here is that the network includes people Maria does not directly relate to: she named them only because they belong to the company.

There are people in the company I ignore. I mean, they are there, but I do not know them. I do not think they are unpleasant, but I have no interest in knowing them. I consider them friends anyway, but I do not want to know what they do in their life. FD28

The company mostly provides companionship, as Maria spends all her free time within it. But even if she is a woman, the relationship does not become intimate neither with other women: Maria does not like to talk about her private matters even when she faces difficult moments. When she split up with her boyfriend the emotional support she received from her friends was expressed through shared activities rather than dialogue, following a typical masculine pattern. It is hard here to distinguish the psychological features from the structural ones. Maria does indeed avoid a deep friendship where inner thoughts are involved: this could be due to her previous romantic experiences, that all ended up with a betrayal from the partner and a close friend. Every time Maria had confided her relationship problems to a female friends she found out the woman used the information to get closer to her partner. The disappointment has marked her capability to trust in intimate bonds:

At the moment I do not want anyone. I am angry, thus I avoid any kind of relationship with a man. I tend to chase them away: I reckon that after a deep disillusion, after someone has teased, betrayed and treaded on you it is normal to react like I am doing. FD28

Within a company, in which the quality of bonds is hidden behind the size of network, it is easier to avoid an intimate relationship, while this would not be the case in a small clique.

The company of MD35 is completely different from Maria's one. Maurizio is a computer programmer who lives on his own in the north suburbs of the city. He named 13 male friends, 10 of them are structured within a clique, two girls he met at school and Marco, a new friend (Fig. 2).

He met Arialdo and Iuri during the national service and they introduced him to the other friends in the clique, acting as bridging ties. The men within the clique collectively define themselves as the family: Maurizio used the English term as he explicitly refers to the typical North European family of choice. The expression itself confirms the hypothesis of the centralization of affective life around friendship (Roseneil and Budgeon, 2004). Friends here are considered the elective family that provides all kind of support Maurizio needs: unlike Antonia (whose network was presented in Section 4.1), men in this company share the same kind of interests, from nights out to the gym to exotic holidays. Thus, Maurizio does not feel a lack of companionship, and his life seems to be completely satisfied.

The company developed a set of rituals marking the belonging to the family: they have a bar where they meet up after work, they go to Laura's house for special occasions like the Easter dinner (that they call "the dinner for the abandoned", referring to people who remain in the city during holidays), on Fridays and Saturdays nights they often go to a local pizzeria before going to their favourite club, they all have a copy of Arialdo's house key, where they usually end up after clubbing.

The network is also a source of emotional support, as the men discuss their personal matters within the family even if some ties are more specialised than others: Maurizio prefers to confide to Iuri and Marco and to Rosella and Elena. Due to the fact that the two women live out of Milan, they are specialised only in emotional support, as Maurizio does not see them very often. The family is also a source of material support, exchanging small favours like borrowing the car and doing the shopping. Here, what is interesting is the heterogeneity of professional skills: Roberto is the doctor everyone goes to when a prescription is needed; Roland is the fitness trainer who gives advices on working out; Maurizio is the computer expert providing software and fixing personal computers; Oscar is the financial account who takes care of economic interests. Material support thus goes beyond the daily favour and represent a valid source of saving money. With such a complete everyday support the family seems to be not only a cohesive subgroup, but also more self sufficient and more satisfying than Maria's company. While the woman express a strong sense of disillusion about affective relationships that also informs friendship, Maurizio, with his group of golden bachelors, perceives his singleness in terms of choice rather than refusal of coupled life and he does not exclude for the future that he might form a family of his own, even if he does not feel this need at the moment.

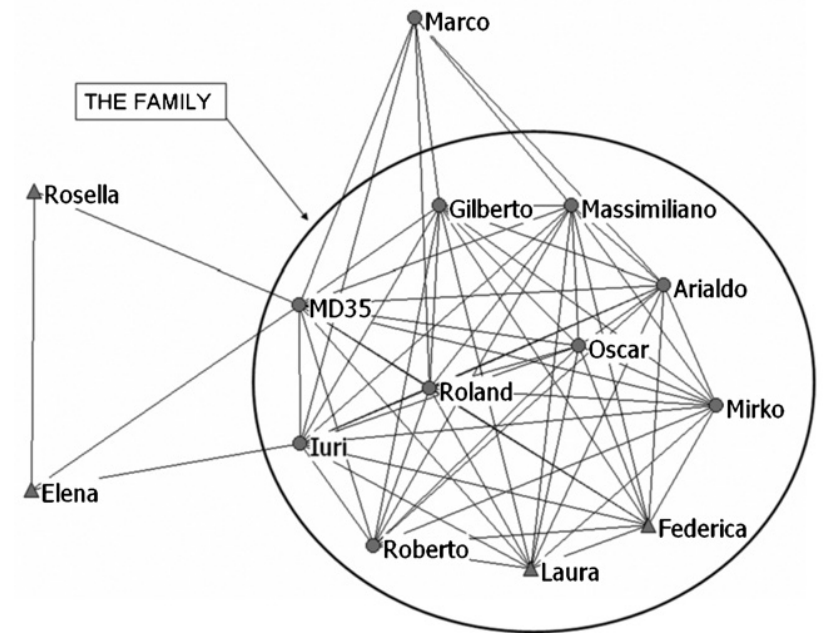

Size: 14 nodes

Density: 0.76

Circle $=$ Male

Up triangle $=$ Female

Fig. 2. Friendship network of MD35. 


\subsection{The core/peripheries structures}

The third typology of networks consists in a structure of variable size (from 16 to 20 nodes) and with a density less than 0.74 . Four people show this kind of structure, a man and a woman who attended university and a man and a woman who went to high school. Here we find a cohesive core of long lasting friends and less dense peripheries specialised in social support. These structures follow a core/periphery model in which the core density is high (=1) and peripheries mostly interact with the core (Everett and Borgatti, 2000). We defined the core as a very cohesive subgroup that provides multiplex support and whose ties are older than the others, while peripheries are generally less dense, more recently formed and specialised. Following Granovetter definition of the strength of a tie, that depends on the "(probably linear) combination of the amount of time, the emotional intensity, the intimacy (mutual confiding) and the reciprocal services which characterise the tie" (Granovetter, 1973: 1361), we can consider the core relationships as strong ties, while periphery ties are weak and more dependent on the contest they develop and are sustained in.

Vittoria is 31, she has got a degree in English and French, she lives on her own in a flat downtown, she works at the American consulate and she plays as a disc jockey and vocalist for hip hop clubs. Her network is shown in Fig. 3 where the size of lines indicates the strength of the ties. These thicker lines represent the bonds with the core friends, whom Vittoria has known since school and shares inner thought and personal problems with: these friends are long standing, they request the most emotional investment, they provide intimacy and according to Vittoria's description the relationship with them entails reciprocal action, as she assures they would always be there for her in case of needs and vice versa. The other peripheral nodes are friends she spends her free time with, whom she shares specific interests with, like music and dance passion, and whom she met more recently:

There are confidant friends, the closer ones, the ones who know me better. Then there is the wider circle of superficial friends, the ones I go out with for an aperitif, to the cinema, to a concert. FL31

While closer friends are considered irreplaceable and represent a long lasting core in Vittoria's life (density within the core $=1$ ), the peripheral friends (density within the periphery $=0.26$ ) are distinguished by the kind of activity she shares with them: Sonia, Giusy, Davide, Alby are counted as dance friends because they attend the same dance course; the writers are people she organises hip hop events with; Davide's friends and Simo's friends are people she goes clubbing with; the radio friends offer her collaborations to radio programs and the French friends include people she met when she did an Erasmus project in France. The collective name can indicate a kind of activity (going to the same dance class), a place where they meet (she sees the French friends only when she goes to France) or the names of people who introduced the new friends to her (Davide and Simo who have acted as bridging ties in the past). While they are generally specialized in offering companionship, within these groups there might be people who do not provide any kind of support, but are still considered friends as they belong to the collective group that define themselves: for example, within Simo's friends Vittoria gets along better with Veronica, whom she has recently met, while the other two women (Elena and Vanessa) are just people she randomly met when they all decide to go clubbing. None of these girl are named in the network (the node is collectively called Simo's friends), but during the interview she goes in details explaining who are these people and what kind of relationship there is between them. The relationship with these friends can be intended as the contextualised friendship described by Adams and Allan (1998) as a tie that depends on the context it was formed and developed into and thus is weaker than other relationship, because a change within the context (like for example a change of interest) can entail a loss of the tie.

This could be the case, for example, of a new romantic relationship. While talking about her friends, Vittoria often refers to her experiences of love: she had dated some men in the past, and she reports that every time she started seeing someone, she had to cut off the time dedicated to friends. In these cases, the network was reduced only to the core (similar results were found by Kalmijn, 2003; Bidart and Lavenu, 2005; Bidart and Degenne, 2005), as she always managed to keep in touch with her intimate friends, while peripheral friends become "fossil" (Spencer and Pahl, 2006: 74). More interestingly, she said that the core people are also the ones she always introduces her new boyfriend to. Like the traditional family in the past, meeting the core friends has become a very important step in a romantic relationship. If the friends do not like the boyfriend, it is harder for the relationship to become serious: core friends know her very well, and she trusts their judgments, so if these are negative, she takes them into account in evaluating the romantic relationship.

A new love does not know me as they do. Then there is obviously the excitement of novelty, but there is also the feeling to recover

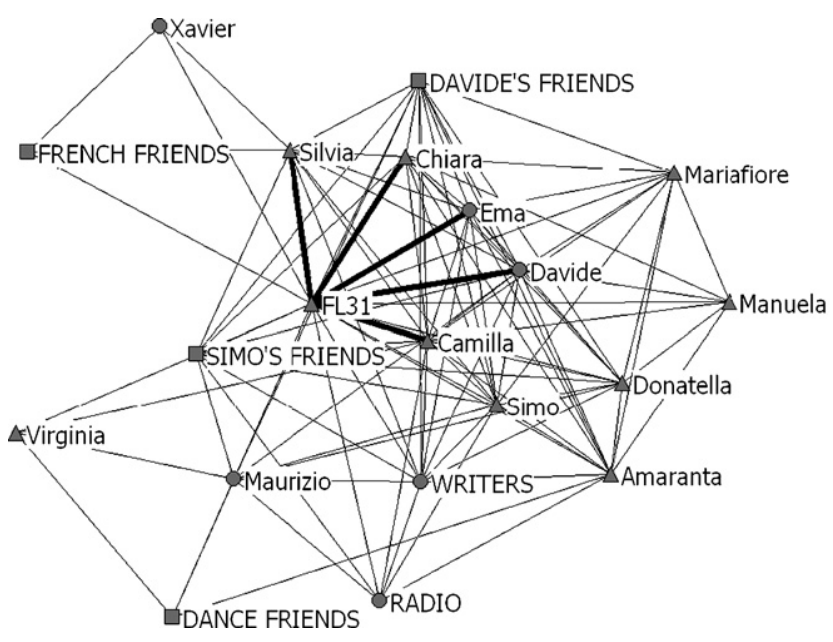

Size: 20 nodes

Density: 0.56

Circle $=$ Male

Up triangle $=$ Female

Square $=$ Collective names

Fig. 3. Friendship network of FL31. 


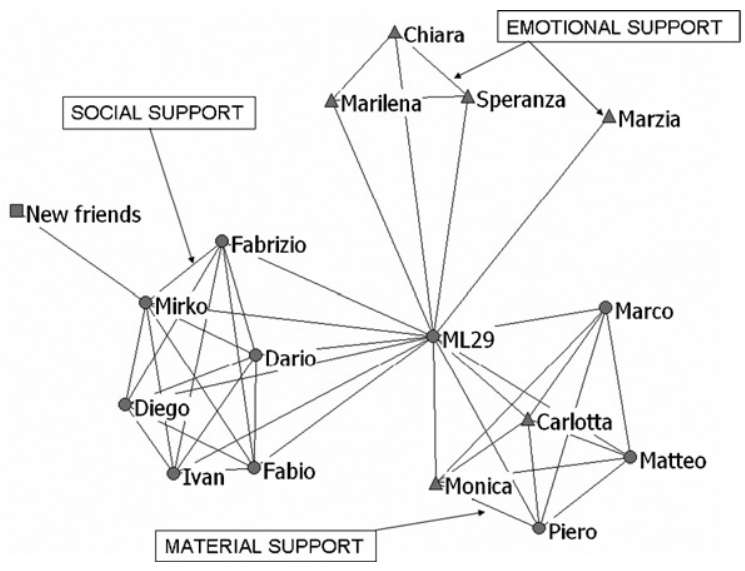

Size: 16 nodes

Density: 0.52

Circle $=$ Male

Up triangle $=$ Female

Square $=$ Collective names

Fig. 4. Friendship network of ML29.

in the safe circle, the one that represents my family. And there is also the delicate moment in which the new lover is introduced to friends. What if they do not like him? I might be madly in love, what do I do? Do friends come first? But also giving priority to the man is a pain in the heart. FL31

Here as well the woman refers to her friends in terms of family: they represent the family of choice, the safe nest where it is possible to recover and that it is hard sometimes to leave behind (Watters, 2003). This enforces again the hypothesis of a centralization of affective life around friends, but also gives the possibility to reformulate the thesis of the "long family" who seems to impede the process of gaining independence for young adults (Scabini and Donati, 1988): here the family that seems to slow down the selection of a romantic partner is not the parents' one but the friends' one.

\subsection{The contextualised networks}

The last network typology we found is composed by small, independent and cohesive subgroups specialised in a specific kind of support. Three people show this kind of network: two men, an undergraduate student and one who went to secondary school, and a graduated woman.

The undergraduate student is Simone, a 29 years old man who studies engineering and lives with his parents and siblings in a semi central area of Milan. Simone's network includes three cliques (see Fig. 4). The group on the low left provides companionship: it is a clique of friends ego met when he was a teenager. These men always hang out together, they go on holiday, they support the same hockey team and see matches on a weekly basis. What is interesting here is that despite the fact that they have known each other for a long time, they do not talk about private matters: following the main male pattern of friendship, they have a side by side kind of relationship, based on shared activities.

The emotional support is provided by the group on the top: it is a clique of women who live in a city near Milan. Simone does not see them very often, but they are the people he refers to when he needs to talk about private topics. They discuss family troubles, love relationships, friendship matters, anything ego does not want to talk about with the male friends of the companionship clique. The same role is played by Marzia, who is Simone's ex girlfriend. She lives in the South of Italy, thus Simone sees her very rarely but often speaks to her at the phone. The physical distance does not imply an emotional one: they talk about everything and he considers the woman his best friend, as he feels like she is always there when he needs to talk.
Finally, the group on the low right represents the material support. It is a clique of friends he daily meets at university: in this case the relationship is based on reciprocal help in dealing with practical tasks, like studying together for exams, sharing lectures' notes, finding books and helping with bureaucracy. Sometimes they go out for an aperitif after a day of studying, but ego does not consider them in terms of companionship.

The specialization on the kind of support here is explicitly gendered, as Simone says during the interview:

I have always been comfortable with Speranza: when I split up with Marzia I needed a girlfriend to talk to without any sexual or romantic implications. I needed a best friend with whom the relationship was deeper than a superficial acquaintance. I do not know why but I felt I needed a female figure. ML29

Simone gives credit to his female friends - especially Speranza and Marilena - about their capability to listen and comprehend, a capability that is different from male friends whom the relationship is limited to sharing activities.

Although it is not characterised by emotional support, the companionship male clique is interesting as it exemplifies the cohesive effect of network on dyads. Simone reports he recently had a critical discussion with Mirko ended up with an argument that also involved the other friends within the clique (everyone was taking side for Simone). Mirko felt excluded and judged and started to go out with other people, loosening the bonds with Simone and the others and investing in new ties that shift the affective centre of Mirko's network (see Fig. 4). Here the cohesiveness of the clique played an important role avoiding the ending of Simone and Mirko friendship. Having many friends in common, the two men often see each other: this prevents them from totally losing the bond, even if it is not as intense as it was in the past, and opens up the possibility for a reunion in the future. Simone does not exclude Mirko from the friendship network, while we can reasonably argue that it would be the easier case if the relationship was only dyadic.

\section{Discussion}

The different typologies of networks show that friendship can be a source of multiplex support for single young adults and that this is differentiated according to the tie strength, but also that friends can be in the network even if they do not provide any kind of support: these kind of friends are there mostly because they belong to cliques or have been important for ego in the past, and these are the ties that would be missed if we asked the interviewees to name people according to whom do they go to when something specific 
is needed. A qualitative interview instead allows us to describe the evolution of a tie, from what did it represent in the past to what does it mean today.

Across the network we can underline three main strategies of affective investment in friendship. The first one consists in obtaining companionship, emotional and material support from a unique friend, who represents a surrogate of a partner. This is the strategy of Antonia, who intends friendship as an exclusive dyadic relationship. According to her definition a friend is a soul mate whom she shares daily experiences with: such a relationship is so similar to romantic love that it does not stand other friends, but it is also hard to maintain as it violates the lightness of friendship (Alberoni, 1984). Every time Antonia found this kind of friend she has also been betrayed and left alone: between the friend and her there has always be someone who stood on the way (FM31).

The second strategy is the one of the company. Here individual needs are not satisfied by a unique person, but by a cohesive group of friends within which ties can be differentiated according to the strength and the kind of support. This is the case of Maurizio, who obtains different and complementary kind of support from the family, that makes me feel protected, it is like a family of choice because we know we can always count on each other (MD35). While the first strategy can be considered as a way to substitute a partner, the second one is a way in which friendship replaces some of the functions of traditional family, especially regarding introducing to friends a new partner and celebrate with them ritual ceremonies (like Easter or Christmas).

The third strategy is the one by which friends are characterised by a specific kind of support. It could be the case of a core of intimate friends and a periphery that provides companionship (like the case of Vittoria), or the case of independent cohesive subgroups specialised on one type of support (like in the case of Simone). Here intimate friends can be seen as a substitute for the original family, as they absolve some of its traditional functions.

It is undeniable that the structure of independent cohesive subgroups is very similar to the one described by Burt (1992). But there are several reasons for which we do not want to apply the structural holes model here. First of all, we cannot be sure that there are no ties between the cliques. Ego could not be aware of relationships that exist between his friends, thus we cannot define this structure in terms of structural holes. According to Granovetter (1973), there is a high chance that because the relationships that link ego to his friends can be considered as strong ties, also the friends can be linked together at least with weak ties. Secondly, in order to use Burt's concepts, we should refer to friendship in terms of social capital. If we do that, then we could also see which structure, between the ones we found, is more efficient in terms of trust and reciprocity. The problem is that within this framework we take for granted that friendship must imply trust and reciprocity, while according to our data this is not always true. Some people report situations in which the friends have betrayed them, or did not show gratitude back when they received favours. But because they also are linked to other friends (like the case of Simone and Mirko), ego still names them as friends. Friendship is thus not always the perfect relationship that they would like to have, and it would be interesting to analyse in which cases it is really based on trust and reciprocity, and when instead the routine that comes from a long lasting relationship prevails over the quality of the tie. Finally, Burt's studies refer to structural holes in terms of competitive advantage in getting and controlling information. Competition and information control can be found in friendship as well, but it is not the main trait of this kind of relationship, at least for the people we interviewed. Thus, Burt's theory is very useful if applied to contexts in which relationships are mainly instrumental, but further research need to be done in order to generalise it to affective ties.
The emotional support provided by friendship seems to be a valid source of community identity as through confidences people compare different life experiences, reinforce reciprocal trust and construct a satisfying single identity. Companionship is useful to diminish the perception of loneliness, as it grants a sense of belonging that coupled people normally obtain from their partner. Material support is a source of reciprocal solidarity, but also highlights class differences (Allan, 1979; Adams and Allan, 1998). People with low incomes count more on friends' informal help that can be seen as a strategy to save money. This is the case of Tiziano, but there are more examples supporting this thesis. Giuseppe is a 28 -year-old unemployed who left school when he was fifteen. He reports how friends helped him in a difficult situation (he spent 2 years in prison), lending money, buying food for his family (he lives with his mother and sister) and offering temporary jobs once he came out of jail.

Due to the qualitative nature of this study we cannot generalise our results. But our findings suggests that when a friendship network provides identity, trust and reciprocity (and we saw this is not always the case) we can consider it a contemporary form of elective community: the main differences with the traditional one is that this one takes place only in private life, as the kind of support it provides does not have a public visibility. Thus, it is not considered by the recent debate on the loosening of community that refers to the decreasing percentage of civil engagement starting from the less involvement into institutionalised forms of associations (Putnam, 2000).

A special mention has to be done for the gender issue. The traditional differences of masculine and feminine friendship styles also emerge from this qualitative study: women seem to be specialised in asking and offering emotional support through face to face dialogue. However men demonstrated the need to share intimacy and confidences as well: they often count on female friends as a source of emotional support (like in the case of Simone), but there are also cases in which personal disclosure happens between men (like in the case of Maurizio). On the other hand, the case of Maria shows how women do not necessarily base their friendship on dialogue: previous experiences can obstruct the formation of intimate and trustful ties reducing friendship to solely companionship. However gender differences are a complex task that needs further research: for example, previous studies suggested that women's friendship networks tend to be smaller than men's because the higher intimacy requires a deeper emotional effort (Allan, 1979; McRobbie, 2000). Instead the women we interviewed have named slightly larger networks than men (12.09 average size of female networks compared to 10.75 average size of male networks). Also, their networks are more heterogeneous in respect of gender: the men named $71.3 \%$ of same sex friends, while the percentage goes down to the $62.4 \%$ for same sex friends in female networks.

\section{Open questions and future research plans}

This qualitative study shows interesting data regarding friendship styles differentiated by gender and social class: data partially confirm the hypothesis found in the previous literature, but also highlight the extreme variability and complexity of subjective experiences that need further research. A qualitative study like the one presented here does not allow us to generalize the findings, but it is useful to pose further research questions and to suggest possible fields of exploration.

First of all the purposed typologies of friendship networks cannot be considered exhaustive: a statistical representative survey could find other kind of networks, correlate them to sociological variables and count how they are distributed within a population. 
Further qualitative studies on the other hand could indicate which networks are more efficient in granting a satisfying single identity. It would also be of some interest to include in the study different geographical areas, like small towns and villages: it is possible to find substantial differences between urban and rural friendship networks, but it is not taken for granted that they have to be denser, smaller or better outside the city. Actually, according to Fischer, "the more urban the community, the more nonkin respondents named" (Fischer, 1982a: 56) Taking the community debate back to the original spatial dimension could be then useful to further explore the dichotomy between community and society which dominated most of the classic sociology. Further investigations on gender issue could also suggest new patterns of feminine and masculine identity which overcomes the stereotyped gender roles in providing support and shaping the friendship networks.

Finally, longitudinal studies on friendship networks, like the one lead by Bidart and Lavenu (2005) could reinforce or confute the hypothesis of a centralization of single intimate life around friendship. If it is true that young adults are showing new cultures of intimacy, we need to investigate how these relational styles can last along the life course. When important events occur or new emotional needs and family responsibilities rise up, the time for friendship could diminish and lose the significance it had for youth, entailing a deep network restructuring in which we have to explore if friends will still be there.

\section{Acknowledgement}

I am grateful for the advice of Russ Bernard and Martin Everett.

\section{References}

Adams, R.G., Allan, G. (Eds.), 1998. Placing Friendship in Context. Cambridge University Press, Cambridge.

Alberoni, F., 1984. L'amicizia. Garzanti, Milano.

Allan, G., 1979. A Sociology of Friendship and Kinship. George Allen and Unwin, London.

Aristotele, 1992. Eudemian Ethics. Oxford University Press, Oxford.

Bagnasco, A., 1999. Tracce di comunità. Il Mulino, Bologna.

Banfield, E.G., 1958. The Moral Basis of a Backward Society. Free Press, New York.

Bauman, Z., 2000. Liquid Modernity. Polity Press, Cambridge.

Bauman, Z., 2001. The Community: Seeking Safety in an Insecure World. Polity Press, Cambridge.

Bauman, Z., 2003. Liquid Love: on the Frailty of Human Bonds. Polity Press, Cambridge.

Bellah, R.N., 1985. Habits of the Heart: Individualism and Commitment in American Life. University of California Press, Berkeley and Los Angeles.

Bernard, R., Johnsen, E.C., Killworth, P.D., McCarty, C., Shelley, G.A., Robinson, S. 1990. Comparing four different methods for measuring personal social networks. Social Networks 12, 179-215.

Bidart, C., 1991. L'amitié, les amis, leur histoire. Représentations et récits. Sociétés Contemporaines 5 , mars.

Bidart, C., 1997. L'amitié. Un lien social. La Découverte, Paris.

Bidart, C., Degenne, A., 2005. Introduction: the dynamics of personal networks. Social Networks 27, 283-287.

Bidart, C., Lavenu, D., 2005. Evolution of personal networks and life events. Social Networks 27, 359-376.

Bott, E., 1956. Urban families: the norms of conjugal roles. Human Relations 9, 325-342.

Burt, R., 1984. Network items and the general social survey. Social Networks 6, 293-339.

Burt, R., 1992. Structural Holes. Harvard University Press, Cambridge.

Calhoun, C., 1998. Community without propinquity revisited: communications technology and the transformation of the urban public sphere. Sociological Inquiry 68 (3), 339-373.

Cavalli, A. (Ed.), 1985. Il tempo dei giovani. Il Mulino, Bologna.

Di Nicola, P. (Ed.), 2003. Amici miei: fenomenologia delle reti amicali nella società del benessere. F. Angeli, Milano.

Di Nicola, P., 2002. Amichevolmente parlando: la costruzione di relazioni sociali in una società di legami deboli. F. Angeli, Milano.

Durkheim, E., 1984. The Division of Labour in Society. Palgrave MacMillian, Basingstoke.
Elliot, A., Lemert, C., 2006. The New Individualism. The Emotional Costs of Globalization, Routledge, London.

Etzioni, A., 1993. The Spirit of Community: Rights. Responsibilities and the Communitarian Agenda, Crown, New York.

Everett, M.G., Borgatti, S.P., 2000. Models of core/periphery structures. Social Networks 21 (4), 375-395.

Fehr, B.A., 1996. Friendship Processes. Sage, London.

Fischer, C.S., 1982a. To Dwell Among Friends. Personal Networks in Town and City. The University of Chicago Press, Chicago and London.

Fischer, C.S., 1982b. What do we mean by 'friend'? An inductive study. Social Network 3, 287-306.

Fischer, C.S., 2005. Bowling alone: what's the score? Social Networks 27, 155-167.

Gans, H.J., 1999. Urbanism and suburbanism as ways of life. In: Waters, M. (Ed.), Modernity: Critical Concepts. Routledge, London.

Garret, S., 1989. In: Porter, R., Tomaselli, S. (Eds.), Friendship and the Social Order. The Dialectics of Friendship, Routledge, London \& New York.

Ghisleni, M., Rebughini, P., 2006. Dinamiche dell'amicizia. Riconoscimento e identità. F. Angeli, Milano.

Giddens, A., 1994. The Transformation of Intimacy. Sexuality, Love and Eroticism in Modern Societies. Polity Press, Cambridge.

Gifford-Smith, M.E., Brownell, C.A., 2002. Childhood peer relationships: social acceptance, friendships, and peer networks. Journal of School Psychology 41, 235-284. Giordano, P.C., 2003. Relationships in adolescence. Annual Review of Sociology 29, 257-281.

Gouldner, H., 1987. Speaking of Friendship: Middle-class Women and Their Friends. Greenwood Press, Westport.

Granovetter, M., 1973. The strength of weak ties. American Journal of Sociology 78 (6), 1360-1380.

Heat, S., 2004. Peer-shared households, quasi-communes and neo-tribes. Current Sociology 52 (2), 161-179.

Heat, S., Cleaver, E., 2003. Young, Free and Single? Twenty-some things and Household Change. Palgrave Macmillan, New York.

Kalmijn, M., 2003. Shared friendship networks and the life course: an analysis of survey data on married and cohabiting couples. Social Networks 25(3), 231-249.

Levin, I., 2004. Living apart together: a new family form. Current Sociology 52 (2), 223-240.

Marsden, P.V., 1987. Core discussion networks of Americans. American Sociological Review 52 (1), 122-131.

Marsden, P.V., 2003. Interviewer effects in measuring network size using a single name generator. Social Networks 25 (1), 1-16.

McCallister, L., Fischer, C., 1983. A procedure for surveying personal networks. In: Burt, R., Minor, J. (Eds.), Applied Network Analysis. Sage Publications, London.

McRobbie, A., 2000. Feminism and Youth Culture. Routledge, London.

O’Connor, P., 1992. Friendship Between Women. A Critical Review. Prentice Hall, Indianapolis.

O'Connor, P., 1998. Women's friendships in a post-modern world. In: Adams, R.G., Allan, G. (Eds.), Placing Friendship in Context. Cambridge University Press, Cambridge.

Pareto, V., 1963. A Treatise on General Sociology. Dover Publications, New York.

Putnam, R.D., 2000. Bowling Alone: the Collapse and Revival of American Community. Simon\&Schuster, New York.

Roseneil, S., Budgeon, S., 2004. Cultures of intimacy and care beyond 'the family': personal life and social change in the early 21 st century. Current Sociology 52 (2), 135-159.

Scabini, E., Donati, P. (Eds.), 1988. La famiglia 'lunga' del giovane adulto. Verso nuovi compiti evolutivi. Vita e Pensiero, Milano.

Sennet, R., 1978. The Fall of the Public Man. Vintage, New York.

Simmel, G., 1950. The Sociology of Georg Simmel. Free Press, New York.

Simmel, G., 1984. On Women, Sexuality and Love. Yale University Press, New Haven.

Spencer, L., Pahl, R., 2006. Rethinking Friendship: Hidden Solidarities Today. Princeton University Press, New Jersey.

Tönnies, F., 1955. Community and Association. Routledge and Kegan Paul, London.

Watters, E., 2003. Urban Tribes. A Generation Redefines Friendship, Family and Commitment. Bloomsbury, New York.

Weber, M., 1978. Economy and Society. University of California Press, Berkeley.

Wellman, B., 1979. The community question: the intimate networks of east Yorkers. American Journal of Sociology 84 (5), 1201-1231.

Wellman, B., 1982. Studying personal communities. In: Marsden, P., Lin, N. (Eds.), Social Structures and Network Analysis. Sage, Beverly Hills.

Wellman, B., 1990. Different strokes from different folks: community ties and social support. American Journal of Sociology 96 (3), 558-588.

Werking, K., 1997. We are Just Good Friends: Women and Men in Nonromantic Relationship. The Guilford Press, New York.

White, W.F., 1943. Street Corner Society. The Social Structure of an Italian Slum. University of Chicago Press, Chicago.

Williams, R., 1973. The Country and the City. Chatto\&Windus, London.

Wright, P., 1982. Men's friendship, women's friendship and the alleged inferiority of the latter. Sex Roles 8 (1), 1-20.

Wright, P., 1991. Gender role orientations and friendship: some attenuation, but gender differences abound. Sex Roles 24 (9/10), 551-566.

Zweig, P., 1980. The Heresy of Self-Love: A Study of Subversive Individualism. Princeton University Press, Princeton. 